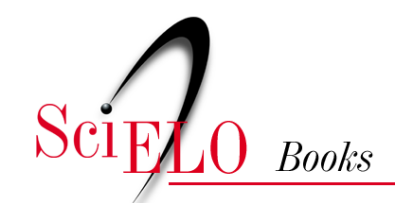

\title{
Introdução \\ Quais relações para literatura e história em Moçambique?
}

\author{
Ubiratã Souza
}

\section{SciELO Books / SciELO Livros / SciELO Libros}

SOUZA, U. Introdução: Quais relações para literatura e história em Moçambique? In: Entre palavras e armas: literatura e guerra civil em Moçambique [online]. São Bernardo do Campo, SP: Editora UFABC, 2017, pp. 1-16. ISBN: 978-85-68576-92-2. https://doi.org/10.7476/9788568576922.0001.

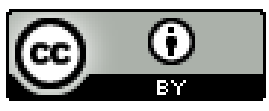

All the contents of this work, except where otherwise noted, is licensed under a Creative Commons Attribution 4.0 International license.

Todo o conteúdo deste trabalho, exceto quando houver ressalva, é publicado sob a licença Creative Commons Atribição 4.0.

Todo el contenido de esta obra, excepto donde se indique lo contrario, está bajo licencia de la licencia Creative Commons Reconocimento 4.0. 


\section{Introdução: Quais relações para literatura e história em Moçambique?}

E acima de tudo, o maior problema é que a história de Moçambique precisa de ser reescrita sem ressentimentos, colocando no lugar apropriado os verdadeiros pais deste país. O que está a acontecer neste momento é a privatização da história de Moçambique, em que alguns moçambicanos se vêem órfãos da sua própria história e isso introduz o que se chama uma categoria de moçambicano de primeira, moçambicano de segunda, moçambicano de terceira, não pode.

$\left(\right.$ Egídio $\left.\mathrm{Vaz}^{2}\right)$

Este é um trabalho sobre literatura moçambicana, um corpo literário nacional que, nas universidades brasileiras, costuma se integrar num campo maior de pesquisa conhecido como "literaturas africanas de língua portuguesa”. Esse campo maior de pesquisa, por sua vez, engloba as literaturas produzidas pelos cinco países africanos que têm a língua portuguesa como língua oficial: Angola, Cabo Verde, Guiné-Bissau, São Tomé e Príncipe e, novamente, Moçambique. O interesse que moveu a pesquisa da qual resulta este livro está, evidentemente, relacionado ao ambiente cultural de crescente valorização do

\footnotetext{
2 "Da guerra de desestabilização a guerra civil": historiador moçambicano fala sobre o conflito entre a FRELIMO e a RENAMO. "Uma viagem, muitos balanços" - 20 anos de paz em Moçambique. Deustche Welle Africa, 2 de out. 2012. Disponível em: <http://dw.com/p/16EY9>. Acesso em: ago. 2016.
} 
conhecimento acerca de África, de que a promulgação da lei 10.639, de 2003, modificada pela lei 11.645 , de 2008, é um efeito considerável. De fato, as referidas leis normatizam a exigência de que sejam ensinados no ensino fundamental e médio de todas as escolas brasileiras conteúdos relativos ao estudo da história e cultura afro-brasileira e indígena.

Segundo o texto da última lei, justifica-se essa exigência devido a "diversos aspectos da história e da cultura que caracterizam a formação da população brasileira, a partir desses dois grupos étnicos", onde se insere a necessidade do estudo da história e cultura de África e dos africanos. A lei está consciente do fato de que o Brasil, em muitos aspectos, é significativamente formado a partir de constituições sócio-históricas retiradas do continente africano por efeito de uma excisão brutal. Mas, se a lei for levada a cabo de modo muito literal, pode parecer que a África só deveria interessar ao Brasil na medida em que aquele imenso continente se integra na formação histórica de nosso país - toda a história de África que abarca o final do século XIX e o borbulhante século XX não deveriam mais despertar questões, portanto.

$\mathrm{O}$ interesse deste livro apresenta-se ligeiramente distanciado desse ponto de vista, por dois motivos: o primeiro, e um tanto óbvio, é o fato de que este livro se debruça sobre duas obras literárias bastante recentes, de 1995 e 2008, respectivamente, que se referem a acontecimentos que tiveram vez em Moçambique entre 1976 e 1992, portanto, tomando parte de uma história bastante contemporânea de Moçambique e de África; segundo, porque este livro parte de uma concepção de que o estudo das diversas literaturas africanas, na medida em que possam ser vistas em face de sua historicidade (porque integram a história contemporânea de África), é pertinente para o conhecimento brasileiro mesmo que eventualmente tratemos de países que não tenham alimentado relações diretas na formação da população 
brasileira (ainda que este não seja o caso de Moçambique, que foi integrado aos últimos fluxos de tráfico humano para terras brasileiras).

Afinal, Moçambique e Brasil são países irmãos, com histórias muito próximas. Ambos os países foram colonizados por Portugal, que fez sua entrada em ambas as terras nas primeiras levas coloniais dos séculos XV e XVI; ambos os países tiveram parte significativa de suas histórias marcada pela integração dos seus territórios a interesses econômicos metropolitanos comuns; ambos os países, devido justamente ao seu histórico colonial, compõem-se de caldeirões culturais imensos; ambos os países têm a língua portuguesa como língua oficial e falada por parcelas significativas das suas populações; ambos os países padeceram das dependências regionais do final da década de 1980 e por quase toda a década de 1990; ambos os países passaram e passam por instabilidades relativas ao estabelecimento de uma democracia sólida; ambos os países apresentam desigualdades sociais imensas e alarmantes níveis de pobreza (e persistentes, malgrado o histrionismo dos discursos oficiais). Enfim, olhar para Moçambique é também olhar um pouco para a trajetória histórica do Brasil face às condicionantes históricas que determinaram os caminhos dos dois países. E a literatura tem muito a contribuir neste sentido.

Afinal, aquele ambiente cultural de crescente valorização do conhecimento acerca de África que teria motivado contextualmente o surgimento deste trabalho tem sido útil para demonstrar o quanto etnocêntrico tem sido nosso ensino e o interesse de nossa intelectualidade durante os séculos. Voltados em demasia para a cultura europeia e americana, parte dos fazedores de cultura brasileiros (professores, pesquisadores, escritores, jornalistas, alunos, estudantes, intelectuais, artistas) perderam oportunidades centrais de se identificarem através da alteridade com países e culturas que comungam dos mesmos percursos históricos que este país trilhou e trilha ainda. Integramo-nos com muita facilidade a um conceito abstrato de "Ocidente", sem 
que possamos perceber o quanto nos distanciamos desse ideal civilizatório que diz muito pouco acerca de nossas realidades culturais.

Mas, para além das inúmeras semelhanças entre o Brasil e os países africanos de língua portuguesa, o conhecimento dessas literaturas é útil justamente para que tanto educadores quanto alunos possam reconhecer-se através da intensa diferença que temos em relação aos moçambicanos, num processo de construção de alteridade cultural. E perceber isso é o primeiro passo para se começar a entender a África em sua imensa pluralidade e diversidade étnico-cultural, longe do ambiente hostil, misterioso e exótico que a cultura eurocêntrica divulgou durante tantos séculos, como justificativa do racismo e da exploração.

Para que possamos também nos reconhecer em Moçambique através da diferença, portanto, é preciso que despertemos o nosso interesse por aprender com aquela cultura, observando os objetos artísticos que dela resultam de um modo totalmente livre de preconceitos e em face da observação de toda a sua integridade social e histórica. Por isso, um trabalho como este, que busca relacionar a literatura e a história de Moçambique face a um contexto específico, é dedicado a um público largo, composto de professores, alunos, estudiosos de literaturas e culturas africanas e afro-brasileiras, e demais interessados que possam surgir pelos temas tangenciais desse trabalho (literatura $\mathrm{e}$ guerra, representatividade social, guerras civis, constituição dos Estados nacionais, culturas pós-coloniais, literatura e história, materialismo histórico e hegemonias, crítica literária e teoria da literatura).

Para esse público, este trabalho é um convite para que todos possam se reconhecer diante de uma realidade que, historicamente, é muito próxima daquela do Brasil, ao mesmo tempo que dela se distancia radicalmente. É um convite, em suma, para descobrir um mundo maior e muito mais rico que os espaços de cultura selvagem e exótica que os veículos de massa tentam provar que existe em África e nos locais proscritos da hegemonia europeia e ocidental, aos quais o Brasil, 
curiosamente, tenta se integrar a custo de toda a diferença etnocultural que o compõe. Face à intensa escassez de materiais sobre esses outros espaços que define o mercado editorial brasileiro, absolutamente ilhado na total dependência das hegemonias globais, este trabalho é um esforço no sentido da divulgação dessas outras possibilidades de estudo e aprendizado.

Para que esta viagem em direção a uma cultura escrita em língua portuguesa produzida no Oceano Índico se dê, no entanto, são necessárias algumas palavras acerca dos trajetos que essa pesquisa palmeou até que resultasse nesta obra que agora se apresenta. Se, por um lado, ela corresponde a um anseio despertado no Brasil de conhecer a África, motivado pela promulgação das referidas leis (ao passo que as leis são também causadas por essa demanda), ela também corresponde a um contexto moçambicano em que as questões aqui tratadas ainda se mostram muito vívidas e consideravelmente complexas. Vamos por partes.

Intitulado Entre palavras e armas: literatura e guerra civil em Moçambique, este livro é uma versão modificada, revista e ampliada de uma dissertação de mestrado defendida em 2014 junto ao Programa de Pós-Graduação em Estudos Comparados de Literaturas de Língua Portuguesa da Universidade de São Paulo. Ele tem como objetivo investigar as relações entre a literatura e a história de Moçambique através da comparação entre dois romances moçambicanos: Os sobreviventes da noite (2008), do escritor Ungulani Ba Ka Khosa, e Neighbours (1995), da escritora Lilia Momplé. Ambos os romances tratam, ao menos em âmbito temático, da conjuntura histórica específica da guerra pós-independência de Moçambique, a qual se convencionou chamar de modos variados: guerra-civil, guerra de agressão, guerra de desestabilização, guerra dos bandidos armados, e, mais recentemente, guerra dos "dezasseis anos" (pelo fato de ela ter durado, aproximadamente, de 1976 a 1992). Trata-se de um trabalho interdisciplinar, 
portanto, que, se por um lado busca investigar as configurações textuais a partir de uma visada estética das obras, por outro, busca investigar as relações que essas configurações estabelecem com toda uma dinâmica sócio-histórica específica recoberta por outras disciplinas humanísticas, como a história, a sociologia, a antropologia, a economia, a ciência política, enfim.

Realizar essa pesquisa dependeu de um esforço de observar e analisar o texto literário moçambicano na sua integridade, atento a todos os fenômenos decorrentes da organização estética das obras enquanto obras literárias, e, a partir dessa observação, construir um modelo crítico-interpretativo de caráter histórico que se esforçasse por estar mais atento à imprevisibilidade do ato crítico do que pronto a aplicar modelos consagrados de interpretação histórico-social da literatura. Esse esforço por criar uma crítica imprevisível acerca do fenômeno literário, quando avançando sobre os terrenos da interpretação histórica, fazia com que a literatura moçambicana entrasse no torvelinho de um acirrado e complexo debate político acerca daquela terrível guerra que se abateu sobre Moçambique logo após a sua independência.

Moçambique tornou-se país independente de Portugal em 1975, após dez anos de uma guerra entre o exército lusitano e a Frente de Libertação de Moçambique - a FRELIMO. A Revolução dos Cravos (1974) em Portugal pôs fim ao regime salazarista que persistia no país desde 1926, para o qual a política colonial era um dos sustentáculos - a partir daquele momento, Portugal aceitou a necessidade de independência das antigas colônias africanas: um governo de transição foi instalado, e no dia 25 de junho de 1975 Moçambique foi oficialmente declarado independente. A partir de 1976, uma nova organização paramilitar, a qual se convencionou chamar de RENAMO (Resistência Nacional Moçambicana), passou a desenvolver ataques armados em todo o interior de Moçambique com uma prática de 
guerrilha de "terra arrasada", destruindo tudo e todos que encontrava pela frente com um grau de barbárie que tocava o horror. Começava então a tal guerra pós-independência, que levou o país à beira do colapso no final da década de 1980, com um saldo de mais de um milhão de mortos e cifras maiores ainda de deslocados e refugiados, desterrados pela guerra e pelas sucessivas secas que se abateram sobre Moçambique no final da década. O conflito chegaria ao fim somente em 1992, após inúmeras rodadas de negociações entre os beligerantes, que comprometia a RENAMO a abandonar as armas e se integrar às estruturas militares do Estado, e a FRELIMO a reconhecer os direitos políticos da RENAMO, e fazer cumprir a democracia multipartidária como forma de governo do país.

Segundo certa abordagem preocupada em pensar o continente africano em vista da autonomia política conquistada pela independência, o termo "guerra civil" precisaria ser execrado, uma vez que através dele corria-se o risco de depositar sobre as populações locais uma agência sobre o conflito que tornava factível uma antiga tese do colonialismo português: a de que os povos africanos ainda não estavam "prontos" para a independência, o que significaria que, caso a independência ocorresse antes de uma suposta hora da maturidade, os africanos matar-se-iam todos em guerras cruéis, por incapacidade de se autogovernarem. Para preencher o vazio da locução "guerra civil”, então, era possível tomar de empréstimo à boca dos governantes o termo "guerra de desestabilização" ou "guerra de agressão", e com ele todo um conceito de que a guerra era tão somente uma agressão do imperialismo capitalista ocidental e do apartheid vizinho que objetivavam "recolonizar" Moçambique e destruir o governo socialista através das forças de "bandidos armados".

Esta visão da guerra não consistia em qualquer equívoco, pois, como veremos, tal guerra de fato se desencadearia através de ataques planejados desde o exterior, e as dinâmicas da Guerra Fria de fato se fazem sentir neste conflito. Mas, circunscrever a guerra somente ao 
âmbito de uma "agressão imperialista" deixaria para trás a necessidade de responder como era possível que uma agressão exterior conseguisse mobilizar tamanha base social, como a que a RENAMO mantém até hoje. Ou ainda, como seria possível que essa agressão exterior, perpetrada primeiramente pela Rodésia do Sul sob o regime apartheísta de Ian Smith, conseguira subsistir tão rapidamente mesmo após a Rodésia se tornar Zimbábue, ou seja, quando o apoio externo cessa, ou arrefece, a guerra parece continuar com cada vez mais força. Era necessário ainda responder, sobretudo, como é que as sociedades moçambicanas percebiam esses conflitos para além das vulgatas políticas e dos discursos oficiais.

Inscrever a guerra pós-independência moçambicana à lógica da Guerra Fria de modo causal e consequente, por fim, era desconsiderar as condicionantes políticas e sociais circunscritas a um espaço efetivamente interno que colidiam para a eclosão e continuidade do conflito: desconsideram-se as questões de política externa específicas da África Austral naquele momento, e ainda mais as condicionantes propriamente moçambicanas que incorrem para o alastramento e prolongamento da guerra. Além disso, insistir tanto na guerra pós-independência somente como uma agressão formulada desde o Ocidente capitalista, era também uma forma de subtrair a ação e o protagonismo da África diante de seus próprios problemas. Ou, como analisa o intelectual camaronês Achille Mbembe, (2001, p. 176):

[...] afirma-se que a África não é responsável pelas catástrofes que sobre ela se abatem. Supõe-se que o atual destino do Continente não advém de escolhas livres e autônomas, mas do legado de uma história imposta aos africanos, marcada a ferro e fogo em sua carne através do estupro, da brutalidade e de todo tipo de condicionantes econômicas.

Por acaso, as recorrências da guerra pós-independência como temática em parte da literatura moçambicana não pareciam ratificar 
esse discurso acerca da guerra (e as recorrências são muito comuns). Pelo contrário, as visões pareciam sempre bastante mais complexas, muito pouco aderidas a quaisquer possibilidades de discurso enviesado, considerando diversos agravantes e diversas variações. Daí o desejo e a necessidade de relacionar a literatura e a história numa pesquisa que contemplasse a questão da guerra pós-independência em Moçambique. Afinal, numa pesquisa centralmente literária, para dizer que a visão de uma guerra se apresenta de modo complexo e pouco enviesado, é necessária uma quantidade de argumentos estéticos bastante relevantes e devidamente relacionados com trabalhos de diversas ciências humanas que possam estabelecer essa relação entre a guerra e a literatura, com o risco de que pesquisa se torne uma grande redução da literatura a simples apêndice de jornalismo.

Este desejo, à altura do processo de elaboração da dissertação original em 2014, não poderia prever que aquela guerra retornaria com fôlego renovado aos noticiários moçambicanos e africanos. Em 17 de outubro de 2012, Afonso Dhlakama, líder da RENAMO, fixou nova base militar no Parque da Gorongosa, na província de Sofala (local histórico de base da RENAMO), e, a partir daí, surgiu novamente o clima de animosidade bélica entre a RENAMO e a FRELIMO, caracterizado por ataques e sabotagens mútuas. Em 21 de outubro de 2013 o exército da FRELIMO cerca e invade a base militar de Dhlakama, e a RENAMO anuncia que estão extintos, depois de onze anos de aparente acalmia, os Acordos de Paz assinados em Roma, em 1992, que haviam posto fim à guerra civil que ocupara toda a década de 1980 (a RENAMO alega que a FRELIMO não cumpriu os estatutos do acordo, e vice-versa). Ainda que os ataques tivessem sido pontuais e não tivessem ocasionado outra guerra generalizada por todo o país, esses acontecimentos foram suficientes para que um grande contingente de civis se deslocasse das regiões afetadas pelos ataques.

No dia 15 de outubro de 2014 novas eleições são encetadas, sob a forte grita que acusa a Comissão Nacional de Eleições (CNE) 
de fraudes eleitorais, como depósito de votos nas urnas antes da abertura oficial das votações, votos duplicados e prisões arbitrárias de observadores em seções eleitorais. Essa eleição, que leva Filipe Nyusi (um engenheiro maconde de Cabo Delgado ${ }^{3}$ ) ao poder, da mesma FRELIMO que está na governação do país desde 1975, agravou ainda mais os combates. A RENAMO não reconhece a legalidade do processo eleitoral de 2014, sobretudo no que se refere às províncias do centro do país historicamente relacionadas com a RENAMO, cuja governação o grupo de Dhlakama reivindica através das armas e de tropas espalhadas pelo país. Em 2017 as conversas avançam pouco no sentido de que a tensão militar se atenue, e o destino desta nova guerra é ainda incerto. Uma trégua anunciou-se na virada do ano, acompanhada da convicção de muitos analistas de que uma revisão constitucional no sentido de se descentralizar a estrutura do Estado possa dar um termo às crises políticas relacionadas com o antigo conflito entre a RENAMO e a FRELIMO.

Esses acontecimentos bastante recentes atribuem novo valor àquela pesquisa. Ela não se detém sobre as intermitências do processo democrático de Moçambique, mas sim sobre a formação da guerra após a independência da maneira como esta aparece em duas obras literárias: Neighbours (1995), de Lilia Momplé, e Os sobreviventes da noite (2008), de Ungulani Ba Ka Khosa. Desse modo, a discussão sobre a história dessa guerra ganha novo fôlego, justamente porque os motivos daquele conflito que assolou o país e vitimou mais de um milhão de vidas ainda parecem estar presentes e passíveis de se reposicionarem rapidamente, em condições que são bastante obscuras até hoje, o que faz com que a democracia moçambicana assuma um caráter frágil,

\footnotetext{
3 A eleição de Nyusi altera uma lógica da política em Moçambique: ele provém de uma geração seguinte àquela que lutou pela libertação, e não tem em seu histórico a luta armada pela independência como algum critério de capital simbólico, como tiveram os demais presidentes do país.
} 
imprevisível e constantemente tenso. A contemporaneidade desse conflito, sobretudo contribui para uma visão menos aderida a ambos os lados beligerantes: nesse caso específico dos acontecimentos presentes, as manifestações da sociedade civil clamando por paz, são sempre exemplos para se perceber o quanto a opinião pública desconhece, compreende e participa muito pouco dos motivos que levam ou levaram aos conflitos. $\mathrm{E}$ isso, porventura, não parecerá necessariamente novidade se tivermos em conta os dois romances sobre os quais esta pesquisa se centra.

Mas, ao dizer que uma pesquisa sobre literatura é importante para a compreensão de uma dinâmica política, saltamos sobre um processo complexo que é articular a investigação estética à investigação histórica - ou, ainda, articular a pesquisa estética à pesquisa historiográfica. E, não por acaso, este não é um trabalho de verificação de como existe um conteúdo histórico que é ficcionalizado em maior ou menor grau por uma literatura mais ou menos comprometida, mas antes objetiva, sim, perceber como certas estruturas estéticas apresentam composições específicas que, se analisadas literariamente, e posteriormente interpretadas historicamente, expõem visões críticas e manifestações sociais que se colocam em articulação com hegemonias que detêm o poder sobre uma sociedade. E esse caminho é uma solicitação da análise literária das obras inseridas no corpus deste trabalho.

Uma rápida leitura do romance Os sobreviventes da noite (2008), de Ungulani Ba Ka Khosa, por exemplo, mostra uma riqueza de tipos humanos, certa complexidade que envolve a composição pessoal de cada indivíduo, uma gama de situações e uma pluralidade de histórias que parecem ser ali mais importantes que qualquer outra possível componente da obra. $\mathrm{O}$ curioso é que toda essa riqueza não está de forma alguma posta na obra como uma forma de festejar uma possível pluralidade cultural: está posta num dos cenários mais terríveis que se possa imaginar, em meio a um acampamento militar, no interior de 
um destacamento composto somente por adolescentes, no fogo cruzado da guerra civil. A humanidade ali aflora de uma condição extrema de sobrevivência, em que as personagens são expostas aos horrores mais escatológicos da guerra, com uma rotina de massacres de vilas e aldeias. Salta aos olhos certo tom de ênfase ao horror e à dissolução de todo um universo; e esse tom cerca qualquer manifestação de sobrevivência no interior da obra. Essa profusão de vidas nessa obra parece estar em prejuízo do próprio andamento da narrativa: o enredo segue um traçado tartamudo, algo confuso, algo prolixo, dentro de uma massa textual tão densa que penetrar na obra consiste um desafio incômodo, uma vez que estamos em pleno ambiente de uma guerra crudelíssima - e nenhum fato absolutamente terrível nos é negado.

Já o romance Neighbours (1995), de Lilia Momplé, é construído de forma um tanto diferenciada: contrariamente ao tempo difuso do romance de Khosa, os capítulos do romance de Momplé são horas de uma noite, e no âmbito de cada capítulo-hora sabemos o que se passa no interior de três apartamentos vizinhos de corredor. Num daqueles apartamentos um atentado é planejado, daqueles que foram comuns na eclosão do conflito armado do qual o romance de Khosa já tratava. Mas, novamente, a gama de tipos humanos e histórias que desfilam diante dos olhos do leitor em cada apartamento é imensa: conseguimos compor até algumas genealogias de certas personagens, conseguimos ter conhecimento de tudo o que se passou para que cada sujeito estivesse ali onde estava nas horas determinadas. Talvez isso também possa ser outro indicativo de uma conveniente oportunidade de proceder a análises que enfatizem a literatura como uma manifestação da experiência humana. Nesse tipo de construção empreendida no romance de Momplé, não é cabível qualquer possibilidade de maniqueísmo ou culpa; mesmo aquelas personagens que estão planejando o atentado, os possíveis algozes do ponto de vista do discurso oficial, têm suas histórias desfraldadas para o leitor, e todo um passado 
de brutalidades e violências ali rememorados, embora não justifiquem seus atos, acabam por mostrar que certas atitudes são, além de previsíveis, inevitáveis, quando estamos numa sociedade que sobrevive presentemente de fracassos resultantes de caminhos e alinhamentos político-econômicos ineficazes para a solução dos graves problemas sociais do país.

A ênfase sobre o detalhe específico da história de qualquer personagem que prende o olhar do foco narrativo e faz que se esqueça do que narrava em tempo presente, as inúmeras digressões, idas e vindas confusas e difusas, parecem ser comuns aos dois romances. A comparação entre eles só pode ser reveladora na medida em que seja possível delinear essa semelhança em perspectiva, ao mesmo tempo que esteja disposta a sublinhar igualmente as diferenças. A presente pesquisa, motivada por essa leitura sinóptica, centrou-se sobre a possibilidade de uma comparação entre as duas obras gerar resultados que fossem relevantes para uma hipótese estética sobre ambas. No entanto, uma vez delineada a hipótese através da análise conjunta, será necessário seguir adiante, num caminho incerto e delicado rumo à história do conturbado momento de Moçambique.

Afinal, se é verdade que a comparação entre os romances é possível justamente porque existe um tratamento estético bastante aproximável em ambos, será mero acaso que, ao tratar de uma mesma conjuntura histórica - o conflito armado dos anos de 1980 -, os romances utilizem formas semelhantes de se estruturar? E se a semelhança não for mero acaso, e estiver em função de alguma possibilidade que transcende a experiência estética em direção à experiência histórica, o que motivaria essa transcendência? Além da motivação, que contributos essa transcendência acrescentaria à possibilidade de analisar essa experiência histórica, que tipo de visão essas obras lançariam para o histórico justamente através da elaboração estética?

Essas são as motivações de um percurso crítico que, justamente por considerar a literatura, desde o princípio, como um ato social 
de cultura, acredita que não seja possível aliená-la das questões precisamente sociais a que ela se direciona e das quais ela advém. Neste sentido, a análise crítica solicita apoio da historiografia, da sociologia, da antropologia política e da economia, justamente porque, ao lado dessas ciências, remonta toda uma condição material de produção. Ao conceber que a sociedade se compõe como um todo, desde suas configurações econômicas até as configurações estéticas de um texto literário, estamos dialogando com o tal princípio materialista das teorias marxistas. São essas teorias inspiradas neste princípio que estão no horizonte provável de toda a construção das versões oficiais da história de África e de Moçambique. Analisar a situação cultural de um país africano à luz de uma teoria de cariz materialista acarreta problemas, no entanto, dos quais nos ocuparemos adiante. Por hora, resta deixar claro que a investigação literária que aqui se propõe buscará justamente estar atenta à necessidade de conectar as dinâmicas estéticas de um texto às dinâmicas sociais circunscritas em uma determinada dinâmica histórica a partir justamente das imprevisibilidades, dos silêncios, das fraturas e dos impasses para os quais o texto pode sinalizar, e nunca consideraremos que os modelos sociais predefinidos muitas vezes por certas correntes do marxismo bastarão para iluminar modos de articulação literária de modo forçoso. Afinal, a ligação entre "literatura e sociedade" no interior de uma crítica voltada à esquerda tem seus problemas já há muito conhecidos, como explana o crítico de esquerda brasileiro Roberto Schwarz (1987, p. 146-147):

No âmbito do marxismo, a ligação entre literatura e sociedade não é uma audácia, é uma obrigação. Nem por isso, feitas as notórias exceções, a situação se afigura melhor. Do ponto de vista de método, comumente estamos num dos casos já aventados: o crítico dispõe de um esquema sociológico, a que a obra serve de confirmação. Se consideramos porém que o dito esquema resume uma versão por assim dizer oficial da história do país, veremos que a dificuldade não é de método, mas de 
política. Entramos no espinhoso problema das relações entre o movimento comunista e a dialética. Limitando-nos a alguns aspectos, digamos que historicamente o marxismo adquiriu feições distantes da intenção crítica original. Tornou-se artigo de fé, a sua exegese se reserva às autoridades competentes, idem para a interpretação da realidade, que é monopólio de instâncias partidárias, e a sua versão da história nacional é defendida como um penhor de congregação antes que de conhecimento. São coisas fáceis de assinalar e difíceis de remediar, pois têm razão de ser profunda. Assim, a par de criticarem o inimigo social designado, estas construções intelectuais têm a função de aglutinar, homogeneizar e controlar o campo de cá. Esta função é conformista no sentido próprio da palavra, e avessa ao espírito crítico. Os estudiosos que se inspiram nela têm forçosamente uma visão instrumentalizada da esfera cultural, em que não vêm novidade, e quando ligam literatura a sociedade é para fazê-la dizer o que já estavam dizendo.

Se considerarmos que o Estado moçambicano se formou sob a égide da inspiração marxista-leninista dos dirigentes da FRELIMO, e que muitos dos problemas apontados a partir da leitura das obras que analisaremos solicitam uma crítica no sentido de se observar de modo distanciado as práticas daquele governo, poderá parecer irônico que este trabalho lance mão de um pressuposto marxista para criticar as realizações do chamado "marxismo real" de Moçambique. No entanto, somente parecerá irônico que este trabalho lance mão de um pressuposto materialista para a análise da literatura e da cultura em Moçambique de modo crítico à esquerda somente se olvidarmos um detalhe da fala de Schwarz, que, de algum modo, norteia este trabalho: "historicamente o marxismo adquiriu feições distantes da intenção crítica original”. Sem conservar a ambição de realizar uma revolução radicalista no interior do marxismo (tanto porque isso é desnecessário) este trabalho busca se localizar à distância de uma articulação metodológica que considere Marx e os marxistas como um "artigo de 
fé": seu objetivo é justamente enveredar pelos pressupostos teóricos de contribuintes significativos dessa abordagem para articular essas fundamentações à leitura dos textos literários.

Motivado por este ímpeto, este trabalho se compõe, a partir do primeiro capítulo, de uma revisita a lugares do debate teórico a respeito de como a crítica literária pode se posicionar de acordo com as hipóteses materialistas diante da cultura, da arte e da literatura. Considerando as possibilidades metodológicas decorrentes do posicionamento teórico, tentaremos encontrar pontos possíveis de articulação para observarmos prováveis homologias entre as configurações literárias e estéticas e as configurações históricas e sociais, perscrutados por diversas disciplinas acadêmicas das ciências humanas. Ainda assim se fará necessário investigar, sobretudo, de que forma essa posição materialista pode ser aproveitada, ou não, para a análise da situação cultural da literatura produzida no continente africano, amiúde em Moçambique - considerando todas as especificidades culturais, sociais e históricas daqueles espaços. Em seguida nos dois capítulos subsequentes, o trabalho mergulha verticalmente em Os sobreviventes da noite e em Neighbours, buscando proceder a uma análise literária das obras, encontrando suas estruturas e modos de funcionamento. No quarto capítulo, os argumentos estéticos extraídos da análise da obra são interpretados à luz do suporte das demais ciências humanas moçambicanas ou sobre Moçambique, de modo que consigamos fechar o ciclo da crítica histórica sobre essas obras. 